\title{
Drug Utilization Evaluation of HMG-COA Reductase Inhibitors in a Tertiary Care Teaching Hospital
}

\author{
Siva S ${ }^{\star 1}$, Shalini Mary John ${ }^{1}$, Bhavya Rajan $\mathbf{P}^{1}$, Roshan $\mathbf{M}^{2}$, Narayana Swami V B $^{1}$ \\ ${ }^{1}$ Department of Pharmacy Practice, Karavali College of Pharmacy, Mangalore, Karnataka, INDIA. \\ ${ }^{2}$ Department of General Medicine, Father Muller Medical College Hospital, Mangalore, Karnataka, INDIA.
}

\begin{abstract}
Drug utilization evaluation (DUE) is an essential component of pharmacoepidemiology, it describes the extent, nature and determinants of drug exposure. It is an ongoing, authorised and systematic quality improvement process, which is designed to review drug use and prescribing patterns, provide feedback of results to clinicians and health care provider. In this context, DUE of HMG-COA reductase inhibitors, the drug of choice for hypercholesterolemia and diseases pertaining to cardiovascular system was studied at MICU, ICCU in a tertiary care teaching hospital. A total of 150 patients were studied over six months period on DUE this includes number of statins, its dose, frequency, duration of treatment and indications. In our study, male genders were more in both ICCU (67.65\%) and $\mathrm{MICU}(56.1 \%)$. Subsequently, rational use of Atorvastatin was found to be more in male patients. Further among HMG COA reductase inhibitors, Atorvastatin was the most prescribed statin in our study period. In addition to this, hypertension accounts as a major distributing risk factor $(21 \%)$ secondary to patient age (37.7\%). Overall, our study demonstrated the importance of DUE and DUE for HMG-COA reductase inhibitors in ICCU and MICU to validate rational use of drugs for minimizing the adverse drug reactions and better treatment outcome.
\end{abstract}

Key words: ICCU, MICU, DDD, Atorvastatin, Rosuvastatin, Cholesterol.

\section{INTRODUCTION}

Drug utilization evaluation can be defined as evaluation of drugs used in a population to determine effectiveness, potential dangers faced by the patients, problems arise due to drug interaction and promotes rational use of drugs. ${ }^{1}$ The intricacy of drug use implies that optimal benefits of drug therapy in patient care may not be achieved because of underuse, overuse or misuse of drugs. Inappropriate drug use may also lead to increased cost of medical care, antimicrobial resistance, adverse effects and patient mortality. Drugs play an important role in improving human health care system. However, to produce desired effect they must be safe, efficacious and must be used rationally. ${ }^{2}$ Therefore, rational use of drug is important to minimize polypharmacy, drug interactions, and reduces hospital stay. ${ }^{1}$

The scope of drug utilization studies [DUS] is to evaluate the current safe and future trends of drug usage to estimate roughly disease pervasiveness, drug expenditures, appropriate prescriptions, and adherence to evidence based recommendations. ${ }^{3}$

Drug utilization research (DUR) is an essential part of pharmacoepidemiology as it describes the extent, nature and determinants of drug exposure. Drug utilization research can be used to compare the observed patterns of drug use for the treatment of a certain disease with current recommendations or guidelines. ${ }^{4} \mathrm{DU}$ research can help to set priorities for the rational allocation of health care budgets. ${ }^{5}$ The aim is to facilitate rational use of drugs in populations, which implies the prescription of a well-documented drug in an optimal dose on the right indication, with correct information and affordable price. ${ }^{3}$
DOI: 10.5530/ijopp.10.4.52

Address for correspondence: Dr. Siva S Assistant Professor, Karavali College of Pharmacy, Mangalore, Karnataka-575028, INDIA. Phone no: 9980990280 Email Id: sivasanumala@gmail. com

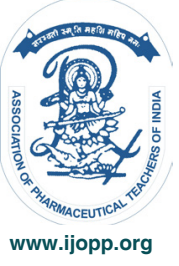


Rational prescription of drugs means an efficient and safe drug according to clinical needs for an adequate period and at the minimum available cost. Prescribing unnecessarily branded drugs, the cost issue, inadequate drugs supply, and lack of patient counselling regarding dosing schedules and possible side effects are the major causes of irrational use of drugs, which may lead to failure of therapy and undesirable side effects. ${ }^{6}$ DUR plays a key role in helping health care system to understand, interpret, and improve the prescribing, administration and use of medication. ${ }^{2}$ Medication quality and patient safety requires a rational prescription of medication and avoidance of inappropriate/ irrational prescribing patterns. ${ }^{6}$

Cardiovascular disease (CVD) is a group of general category diseases that affects the heart and the circulatory system that is heart and blood vessels. It includes coronary heart disease (CHD), congestive heart failure (CHF), stroke, hypertension, peripheral artery disease, and rheumatic heart disease. ${ }^{7}$ In India, Cardiovascular diseases (CVD) is projected to be the largest cause of death and disability by 2020 with 2.6 million. Indians are predicted to die due to Coronary Heart Diseases, which constitutes $54.1 \%$ of all CVD deaths. It is estimated that, nearly half of these deaths are likely to occur among young and middle-aged individuals (30-79 years). ${ }^{8}$

Hyperlipidaemia is the major risk factor for cardiovascular morbidity and mortality. It is the term used to denote raised serum levels of one or more of total cholesterol (TChol), low-density lipoprotein cholesterol (LDL-C), triglycerides (TGs), or both TChol and TG (combined Hyperlipidaemia). ${ }^{10}$

HMG-COA reductase inhibitors are the drug of choice for hypercholesterolemia and diseases pertaining to cardiovascular system. These drugs are currently the most frequently used and best-selling prescription drug worldwide. ${ }^{9}$ Statins reduce CVD events and total mortality irrespective of the initial cholesterol concentration. Adverse effects of statin therapy range from raised liver enzymes to potentially fatal rhabdomyolysis, musculoskeletal complaints. ${ }^{2}$

\section{Defined daily dose (DDD)}

The assumed average maintenance dose of drug per day for adults is called defined daily dose (DDD). DDD can be used as a tool to analyse drug utilization with the goal of improving drug use. ${ }^{2}$

Our study explains in detail about evaluation of prescribing patterns of statins, assessment of rationality of statins in patients admitted in MICU and ICCU and identification of indications for which statins are prescribed. Therefore, drug utilization studies are very essential for evaluating and analysing the drug therapy from time to time, to observe the prescribing patterns of general physicians, with the aim of validating the use of drugs and minimizing the adverse drug reactions. ${ }^{5}$

\section{MATERIALS AND METHODS}

This prospective study was conducted between September 2016 and February 2017 in Multidisciplinary Intensive Care Units, Father Muller Medical College Hospital, Mangalore. The study was approved by Institutional Ethical Committee of Father Muller Medical college hospital, Mangalore (FMMC/FMIEC/3053/2016)

All the patients who were prescribed with HMG-COA reductase inhibitors above the age of 20 years and patients admitted in MICU, ICCU and shifted towards were recruited. The patients were excluded from the study either if they are pregnant women and breast-feeding mothers, Patients who have incomplete data or Patients who have shifted to the wards within $24 \mathrm{~h}$.

A total of 150 patients were included in the study.

The number of statins, its dose, frequency, duration of treatment and indications were noted

Following formulae were used to measure the outcome:

Total in - patient service days

Occupancy index $=\frac{\text { for a period }}{\text { Total in }- \text { patient bed count } \times} \times 100$

number of days in the period

No. of units administered

DDD / 100 bed days $=\frac{\text { in a given period }}{\begin{array}{l}\text { DDD } \times \text { number of day's } \times \\ \text { number of beds } \times \text { occupancy index }\end{array}} \times 100$

Where,

Data were entered Microsoft Excel (Windows 10; version 2010) and analyzes were done. Descriptive statistics such as frequencies and percentages were calculated for categorical variables. Mean and standard deviation were computed for continuous variables. Graphic representation is used for visual interpretation of the analyzed data.

Indian Journal of Pharmacy Practice, Vol 10, Issue 4, Oct-Dec, 2017 


\section{RESULTS}

\section{Demography and patient details}

This prospective study involved 150 patients. Out of which 68 prescriptions were of ICCU and 82 prescriptions were that of MICU.

In ICCU, out of 68 patients analysed, 46 patients were males and 22 were females, these are shown in Figure 1. The maximum number of patients was found in 51-60year age group which was followed by the age group $>70$. Average age was found to be 11.33 (SD \pm 8.13 ). The details are given in Figure 2 and Table 1. Statins prescribed in the population under study included Atorvastatin and Rosuvastatin out of which, 61(89.7\%) patients were prescribed with Atorvastatin alone, $2(2.9 \%)$ patients with Rosuvastatin alone and 5(7.4\%) patients were prescribed with both Atorvastatin and Rosuvastatin which are shown in Figure 3. Average length of stay in ICCU was 17 days $(\mathrm{SD} \pm 14.8)$ as given in Figure 4. Among the patients analysed in ICCU, rural population $(52.94 \%)$ was mostly exposed than the urban population (47.1\%) which are shown in Figure 5. Mostly prescribed dose for Atorvastatin and Rosuvastatin was found to be $40 \mathrm{mg}$ that is $43(44.8 \%)$ and $4(4.2 \%)$ respectively that are shown in Table 2.

In MICU, out of 82 patients analysed, 46 patients were males and 36 were females. The maximum number of patients was found in $>70$ age group which was followed by the age group 61-70. Average age was found to be 13.67 (SD \pm 11.89 ). $77(93.9 \%)$ patients were prescribed with Atorvastatin alone, 2(2.43\%) patients with Rosuvastatin alone and $3(3.7 \%)$ patients were prescribed with both Atorvastatin and Rosuvastatin. These are shown in Figure 3. Average length of stay in MICU was 20 days $(S D \pm 11.14)$. The details are given in Figure 4. Among the patients analysed in MICU, urban population $(58.53 \%)$ was mostly exposed than the rural populations $(41.46 \%)$ as shown in Figure 6. Mostly prescribed dose for Atorvastatin and Rosuvastatin was found to be $10 \mathrm{mg}$ that is $52(49.5 \%)$ and $2(1.9 \%)$ respectively. These are given in Table 3.

\section{Doses prescribed in study population}

Out of 150 patients, 68 were from ICCU and 82 from MICU. 68 patients in ICCU were prescribed total number of 96 drugs during their treatment period. Results revealed that $40 \mathrm{mg}$ of Atorvastatin was prescribed in highest percentage $43(44.8 \%)$ and $20 \mathrm{mg}$ of atorvastatin $24(25 \%)$ followed by Rosuvastatin was prescribed very low, the details are shown in Table 2. And 82 patients in MICU were prescribed total number of 105 drugs during their treatment period. Results revealed that $10 \mathrm{mg}$ of Atorvastatin was prescribed in highest percentage $52(49.5 \%)$ and $20 \mathrm{mg}$ of atorvastatin $24(22.8 \%)$ followed by Rosuvastatin. The details are shown in Table 3 .

\section{Statin utilization pattern in ICCU}

The most commonly prescribed HMG-COA reductase inhibitors (statins) at ICCU was atorvastatin (90.4\%) and 89 units of the same were consumed among the patients studied and Rosuvastatin were least prescribed. Table 4 shows the defined daily dose of Atorvastatin and Table 5 shows the defined daily dose of Rosuvastatin. Most frequently prescribed statins along with their DDD/100 bed days are summarized in Table 6.

\begin{tabular}{|c|c|c|c|c|}
\hline \multirow[b]{2}{*}{ AGE } & \multicolumn{2}{|c|}{ ICCU } & \multicolumn{2}{|c|}{ MICU } \\
\hline & $\begin{array}{c}\text { No. of } \\
\text { patients }\end{array}$ & Percentage (\%) & $\begin{array}{c}\text { No. of } \\
\text { patients }\end{array}$ & Percentage (\%) \\
\hline $20-30$ & 0 & 0 & & 2 \\
\hline $31-40$ & 2 & 2.94 & & 2 \\
\hline $41-50$ & 11 & 16.2 & & 5 \\
\hline $51-60$ & 23 & 33.85 & & 14 \\
\hline $61-70$ & 15 & 22.01 & & 29 \\
\hline$>70$ & 17 & 25 & & 30 \\
\hline Mean \pm SD & \multicolumn{2}{|c|}{$11.33 \pm 8.137$} & \multicolumn{2}{|c|}{$13.66 \pm 11.89$} \\
\hline
\end{tabular}

\begin{tabular}{|c|c|c|c|c|}
\hline Statins & $\begin{array}{l}\text { Percentage of } \\
\text { patients }(10 \mathrm{mg})\end{array}$ & $\begin{array}{l}\text { Percentage of } \\
\text { patients }(20 \mathrm{mg})\end{array}$ & $\begin{array}{l}\text { percentage of } \\
\text { patients }(40 \mathrm{mg})\end{array}$ & $\begin{array}{c}\text { percentage of } \\
\text { patients }(80 \mathrm{mg})\end{array}$ \\
\hline Atorvastatin & $14(14.6 \%)$ & $24(25 \%)$ & $43(44.8 \%)$ & $8(8.3 \%)$ \\
\hline Rosuvastatin & 0 & $3(3.1 \%)$ & $4(4.2 \%)$ & 0 \\
\hline
\end{tabular}




\section{Brand wise distribution of Atorvastatin and Rosuvastatin in ICCU}

Atorvastatin was prescribed in the hospital under different brand names which included Atorva (66.7\%), Atorlip (11.1\%), Aova (7.8\%), Atocor (2.2\%), Atorsave $(8.9 \%)$, Aztor (2.2\%), and Lipitor (1.1\%). Out of these, brand Atorva was found to be mostly prescribed i.e 60 (66.7\%). Rosuvastatin was prescribed under the brand names Rozavel (66.7\%), Rosave (0\%), Roseday (33.3\%). Out of these, brand Rozavel was found to be mostly prescribed i.e $6(8.82 \%)$.

\section{Age wise distribution of rational and irrational use of Atorvastatin in ICCU}

The following shows the age wise distribution of the rational and irrational use of atorvastatin. In this, we found that more people in the age group of 51-60 utilized their medications rationally i.e. $26(30.8 \%)$ and also, we found more number of irrational use of medicines in this same group. Details are shown in Table 7

\section{Age wise distribution of rational and irrational use of Rosuvastatin.}

Table 8 shows the age wise distribution of rational and irrational use of Rosuvastatin. In this we found that more people in the age group of 51-60 utilized their medications rationally i.e. 3(50\%) and also, we found more number of irrational use of medicines in this same group.

\section{Indications for statins in ICCU}

Out of 68 patients in ICCU more number of patients was admitted with indications related with Cardio Vascular System (CVS) 37 (54.4\%) followed by CVS + Endocrine system 19(27.9\%). The details are shown in Figure 7.

\section{Distribution of risk factors in ICCU}

The following table shows distribution of risk factors among statin consuming patients of which, hypertension $32(21.9 \%)$ was found to be the major risk factor, apart from age. The details are shown in Table 9.

\begin{tabular}{ccccc}
\hline \multicolumn{6}{c}{ Table 3: Doses prescribed in study population in MICU } \\
statins & $\begin{array}{c}\text { percentage of } \\
\text { patients(10mg) }\end{array}$ & $\begin{array}{c}\text { Percentage of } \\
\text { patients(20mg) }\end{array}$ & $\begin{array}{c}\text { Percentage of } \\
\text { patients(40mg) }\end{array}$ & $\begin{array}{c}\text { Percentage of } \\
\text { patients(80mg) }\end{array}$ \\
\hline Atorvastatin & $52(49.5 \%)$ & $24(22.8 \%)$ & $16(15.3 \%)$ & $10(9.6 \%)$ \\
Rosuvastatin & $2(1.9 \%)$ & $1(0.9 \%)$ & 0 & 0 \\
\hline
\end{tabular}

\begin{tabular}{cccc}
\hline Table 4: Defined Daily Dose of Atorvastatin. & & \\
\hline Dose & DDD & Units & Total DDD \\
\hline $10 \mathrm{mg}$ & 0.5 & 14 & 7 \\
$20 \mathrm{mg}$ & 1 & 24 & 24 \\
$40 \mathrm{mg}$ & 2 & 43 & 86 \\
$80 \mathrm{mg}$ & 4 & 8 & 32 \\
Total & - & 89 & 149 \\
\hline
\end{tabular}

\begin{tabular}{cccc}
\hline Table 5: Defined daily dose of Rosuvastatin. & & \\
\hline Dose & DDD & Units & Total DDD \\
\hline $10 \mathrm{mg}$ & 1 & 0 & 0 \\
$20 \mathrm{mg}$ & 2 & 3 & 6 \\
$40 \mathrm{mg}$ & 4 & 4 & 16 \\
Total & - & 7 & 22 \\
\hline
\end{tabular}

\begin{tabular}{cccccccc}
\multicolumn{2}{l}{ Table 6: Drug utilization metrics in ICCU. } & & & & \\
Statin & SATC code & Total no. of pts & $\begin{array}{c}\text { Prescribed } \\
\text { strength }\end{array}$ & $\begin{array}{c}\text { DDD } \\
\text { (mg) }\end{array}$ & $\begin{array}{c}\text { Total } \\
\text { DDDs }\end{array}$ & $\begin{array}{c}\text { Total } \\
\text { units }\end{array}$ & DDD/100 bed days \\
\hline Atorvastatin & C10AA05 & 66 & $10,20,40,80$ & $20 \mathrm{mg}$ & 149 & 89 & 7.746 \\
Rosuvastatin & C10AA07 & 7 & $10,20,40$ & $10 \mathrm{mg}$ & 22 & 7 & 1.217 \\
\hline
\end{tabular}




\section{Statin utilization pattern in MICU}

The most commonly prescribed HMG-COA reductase inhibitors (statins) in MICU was Atorvastatin (94.12) and 102 units of the same were consumed among the patients studied and Rosuvastatin were leastly prescribed. Table 10 shows defined daily dose of Atorvastatin and Table 11 shows defined daily dose of Rosuvastatin. Most frequently prescribed statins along with their DDD/100 bed days.

\section{Brand wise distribution of Atorvastatin and Rosuvastatin in MICU}

Atorvastatin was prescribed in the hospital under different brand names which included Atorva (56.2\%),

\begin{tabular}{ccccc}
\hline Table 7: Age wise distribution of rational and irrational use of Atorvastatin. \\
\hline Age & $\begin{array}{c}\text { No of patients with } \\
\text { Rational use of drug. }\end{array}$ & $\begin{array}{c}\text { \%of patients with } \\
\text { rational use of drugs. }\end{array}$ & $\begin{array}{c}\text { No of patients without } \\
\text { rational use of Drug }\end{array}$ & $\begin{array}{c}\% \text { of patients without } \\
\text { rational use of Drugs }\end{array}$ \\
\hline $20-30$ & 0 & 0 & 0 & 0 \\
$31-40$ & 5 & 6 & 0 & 0 \\
$41-50$ & 15 & 19 & 0 & 0 \\
$51-60$ & 26 & 30.8 & 3 & 3 \\
$61-70$ & 20 & 25 & 1 & 1.1 \\
$>70$ & 12 & 14 & 1 & 1.1 \\
\hline
\end{tabular}

Table 8: Age wise distribution of rational and irrational use of Rosuastatin.

\begin{tabular}{ccccc} 
Age & $\begin{array}{c}\text { No of patients with } \\
\text { rational use of drug }\end{array}$ & $\begin{array}{c}\text { Percentage of } \\
\text { patients with rational } \\
\text { use of drug (\%) }\end{array}$ & $\begin{array}{c}\text { No of patients without } \\
\text { rational use of drugs }\end{array}$ & $\begin{array}{c}\text { Percentage of patients } \\
\text { without rational use of } \\
\text { drugs (\%) }\end{array}$ \\
\hline $20-30$ & 0 & 0 & 0 & 0 \\
$31-40$ & 0 & 0 & 0 & 0 \\
$41-50$ & 1 & 16.6 & 0 & 0 \\
$51-60$ & 3 & 50 & 1 & 16.6 \\
$61-70$ & 0 & 0 & 0 & 0 \\
$>70$ & 1 & 16.6 & 0 & 0 \\
\hline
\end{tabular}

\begin{tabular}{ccc}
\hline \begin{tabular}{c} 
Table 9: Distribution of risk factors in ICCU. \\
\hline Risk factors
\end{tabular} & No of patients & Percentage (\%) \\
\hline Age > 50 & 55 & 37.7 \\
HTN & 32 & 21.9 \\
DM & 25 & 17.1 \\
Smoking & 18 & 12.4 \\
Drinking & 16 & 10.9 \\
\hline
\end{tabular}

\section{Table 10: Defined Daily Dose of Atorvastatin.}

\begin{tabular}{cccc} 
Dose & DDD & units & Total DDD \\
\hline $10 \mathrm{mg}$ & 0.5 & 52 & 26 \\
$20 \mathrm{mg}$ & 1 & 24 & 24 \\
$40 \mathrm{mg}$ & 2 & 16 & 32 \\
$80 \mathrm{mg}$ & 4 & 10 & 40 \\
Total & - & 102 & 122 \\
\hline
\end{tabular}

\section{Table 11: Defined Daily Dose of Rosuvastatin.}

\begin{tabular}{cccc} 
Dose & DDD & Units & Total DDD \\
\hline $10 \mathrm{mg}$ & 1 & 2 & 2 \\
$20 \mathrm{mg}$ & 2 & 1 & 2 \\
Total & - & 3 & 4 \\
\hline
\end{tabular}

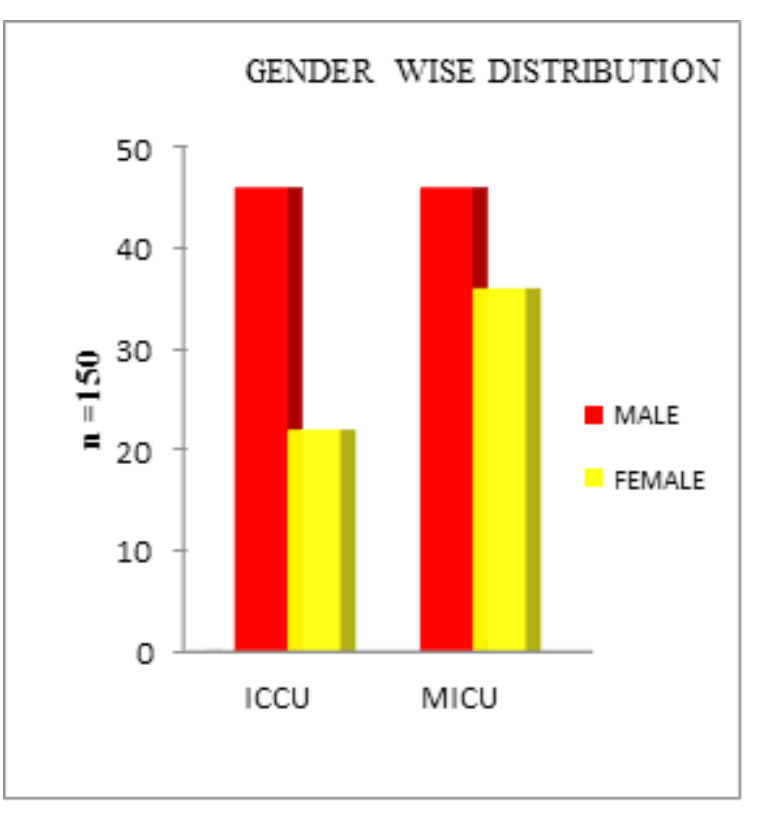

Figure 1: Gender Wise Distribution 
Atorlip (11.4\%), Aova (20\%), Atocor (5.7\%), Atorsave (6.7\%), Aztor and Lipitor ( $0 \%)$.Out of these brand Atorva was found to be mostly prescribed in MICU i.e $59(56.2 \%)$. Rosuvastatin was prescribed in the hospital under the brand names of Rozavel (60\%), Rosave (40\%), Roseday $(0 \%)$. Out of these, brand Rozavel was found to be mostly prescribed in MICU i.e. 3(60\%).

\section{Age wise distribution of rational and irrational use of Atorvastatin in MICU}

Following Table 13 shows the age wise distribution of rational and irrational use of Atorvastatin. Results revealed that more people in the age group of $61-70$ utilized their medications rationally i.e. 34(33.9\%) and also, we found more number of irrational use of medications in this same group.

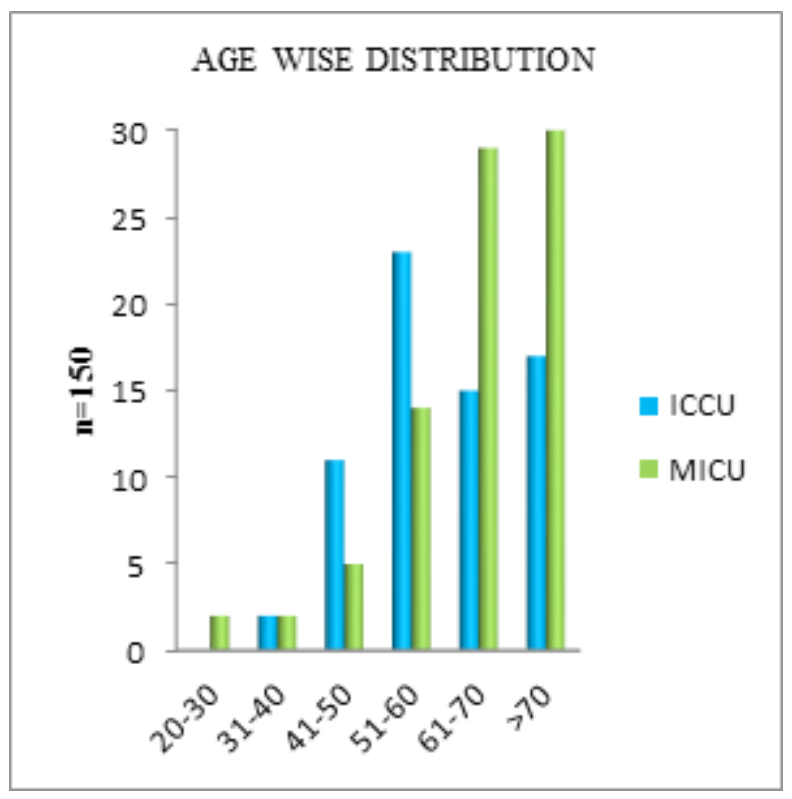

Figure 2: Age Distribution in ICCU \& MICU

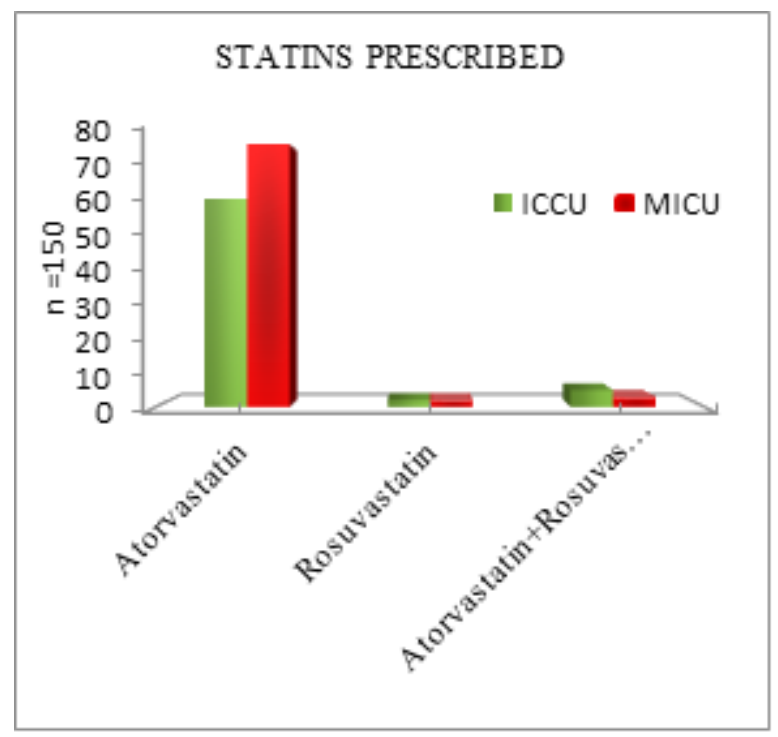

Figure 3: Statins Prescribed

\section{Age wise distribution of rational and irrational use of Rosuvastatin in MICU}

Following Table 14 shows the age wise distribution of rational and irrational use of Rosuvastatin. Results revealed that more people in the age groups 31-40, 41-50, $>70$ utilized their medications rationally i.e $1(25 \%)$ respectively and also, we found more number of irrational use of medicines in the group $>70$.

\section{Indications for statins in MICU}

Out of 82 patients in MICU, more number of patients were admitted with indications related to cardiovascular system (CVS) 26(31.7\%) followed by combination of indications CVS+ endocrine system +CNS 18(21.9\%). The details are shown in Figure 8.

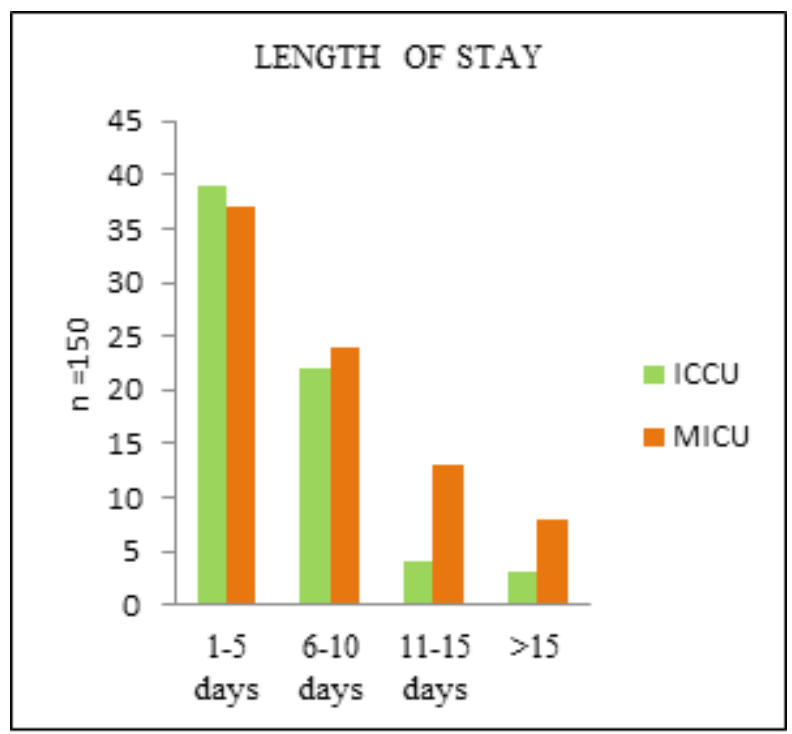

Figure 4: Length of Stay

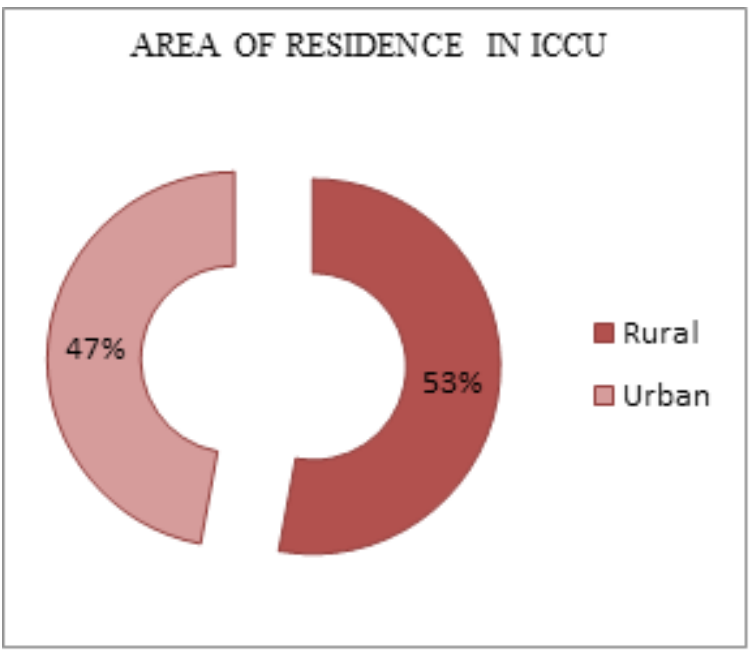

Figure 5: Area of Residence in ICCU 


\section{Distribution of risk factors}

The following shows distribution of risk factors among statin consuming patients of which, hypertension $54(27 \%)$ was found to be the major risk factor apart from age. The details are shown in Table 15.

\section{DISCUSSION}

The role of pharmacist in medical settings has gone through a huge extreme change. Today the pharmacist is not only dispensing the medicines but also has responsibilities like mission of providing drug therapy to a patient to prevent, cure and identifying a disease, sickness/problem or illness. Pharmacist are trained to provide specialist services, health examining, diabetes care, procedures that protects people from disease, patient education and to provide correct information to the healthcare providers related to drugs, disease, nutrition, anticoagulation, germ killing drugs, using effective drugs to help cure disease, cholesterol lowering agents and many more. Pharmacists are trained in the basic rules of drug education, drug findings, drug utilization and quality of something.
Prescriptions of 150 consecutive admissions were audited over 6 Months period to study Drug utilization of HMG-COA reductase inhibitors in a tertiary care teaching hospital. The data was collected from the ICCU and MICU of emergency units of the hospital. In our study, male population was more in both ICCU $(67.65 \%)$ and MICU (56.1\%) followed by females. Our study is correlated with study carried out by Praveen K.G et al.

The age wise distribution of patients in ICCU showed that patients of age group 51-60 constituted the highest number $(33.85 \%)$. Similar findings were observed in studies conducted by Praveen K.G et al. Also age wise distribution in MICU showed age group $>70$ constituted the higher number $30(36.6 \%)$.

Atorvastatin was the most prescribed statin in the whole study. In ICCU, 61(89.7\%) patients were prescribed with Atorvastatin alone, 2 (2.94\%) patients with Rosuvastatin alone and $5(7.35 \%)$ patients were prescribed with both Atorvastatin and Rosuvastatin. In MICU, 77(93.9\%) patients were prescribed with atorvastatin alone, $2(2.43 \%)$ patients with Rosuvastatin alone and 3(3.7\%) patients were prescribed with both atorvastatin and

\begin{tabular}{cccccccc}
\multicolumn{2}{l}{ Table 12: Drug utilization metrics in MICU. } & & & & \\
Statin & SATC code & $\begin{array}{c}\text { Tot no of } \\
\text { pts }\end{array}$ & $\begin{array}{c}\text { Prescribed } \\
\text { strength(mg) }\end{array}$ & DDD(mg) & $\begin{array}{c}\text { Total } \\
\text { DDDs }\end{array}$ & $\begin{array}{c}\text { Total } \\
\text { units }\end{array}$ & $\begin{array}{c}\text { DDD/100 bed } \\
\text { days }\end{array}$ \\
\hline Atorvastatin & C10AA05 & 80 & $10,20,40,80$ & 20 & 122 & 102 & 2.494 \\
Rosuvastatin & C10AA07 & 5 & 10,20 & 10 & 4 & 3 & 0.147 \\
\hline
\end{tabular}

\section{Table 13: Age wise distribution of rational and irrational use of Atorvastatin.}

\begin{tabular}{ccccc}
\hline Age & $\begin{array}{c}\text { No of patients with } \\
\text { rational use of drug }\end{array}$ & $\begin{array}{c}\% \text { of patients with } \\
\text { rational use of drug }\end{array}$ & $\begin{array}{c}\text { No of patients without } \\
\text { rational use of drug }\end{array}$ & $\begin{array}{c}\% \text { of patients without } \\
\text { rational use of drug }\end{array}$ \\
\hline $20-30$ & 2 & 1.9 & 0 & 0 \\
$31-40$ & 2 & 1.9 & 0 & 0 \\
$41-50$ & 6 & 5.9 & 0 & 0 \\
$51-60$ & 17 & 16.9 & 1 & 0.9 \\
$61-70$ & 34 & 33.9 & 5 & 4.9 \\
$>70$ & 31 & 30.7 & 3 & 2.9 \\
\hline
\end{tabular}

\begin{tabular}{ccccc}
\hline Table 14: Age wise distribution of rational and irrational use of Rosuvastatin. \\
\hline Age & $\begin{array}{c}\text { No of patients with } \\
\text { rational use of drug }\end{array}$ & $\begin{array}{c}\text { \%o of patients with } \\
\text { rational use of drug }\end{array}$ & $\begin{array}{c}\text { Notho of patients without } \\
\text { withoul use } \\
\text { of drug }\end{array}$ & $\begin{array}{c}\% \text { of pational use of drug } \\
\text { rational }\end{array}$ \\
\hline $20-30$ & 0 & 0 & 0 & 0 \\
$31-40$ & 1 & 25 & 0 & 0 \\
$41-50$ & 1 & 25 & 0 & 0 \\
$51-60$ & 0 & 0 & 0 & 0 \\
$61-70$ & 0 & 0 & 0 & 0 \\
$>70$ & 1 & 25 & 1 & 25 \\
\hline
\end{tabular}


Rosuvastatin. Average length of stay was found to be 17 days (SD \pm ranging from 6-10 days in ICCU and average length of stay was found to be 20 days ranging from 6-10 days in MICU. In our present study, rural population $52.9 \%$ was most commonly affected than urban population in ICCU like that of Vinod kumar $\mathrm{M}$ et al. Also in MICU, urban population was mostly affected $48(58.5 \%)$.

Statins were prescribed under the strengths of $10 \mathrm{mg}$, $20 \mathrm{mg}, 40 \mathrm{mg}$ and $80 \mathrm{mg}$ depending on the severity of the disease. Among 68 patients in ICCU, $40 \mathrm{mg}$ atorvastatin was mostly prescribed to $43(44.8 \%)$ patients, followed by $20 \mathrm{mg}-24(25 \%)$. This result was like Praveen K.G et al. Also among 82 patients in MICU, $10 \mathrm{mg}$ Atorvastatin was mostly prescribed to $52(49.5 \%)$ patients followed by $24(22.8 \%)$.

WHO has recommended a DDD of $20 \mathrm{mg}$ for Atorvastatin, $10 \mathrm{mg}$ for Rosuvastatin and our usage is in accordance. Data on the utilization of statins was expressed as DDD/100 bed days. DDD is an average assumed maintenance dose per day for a drug used for its main indication in adults.

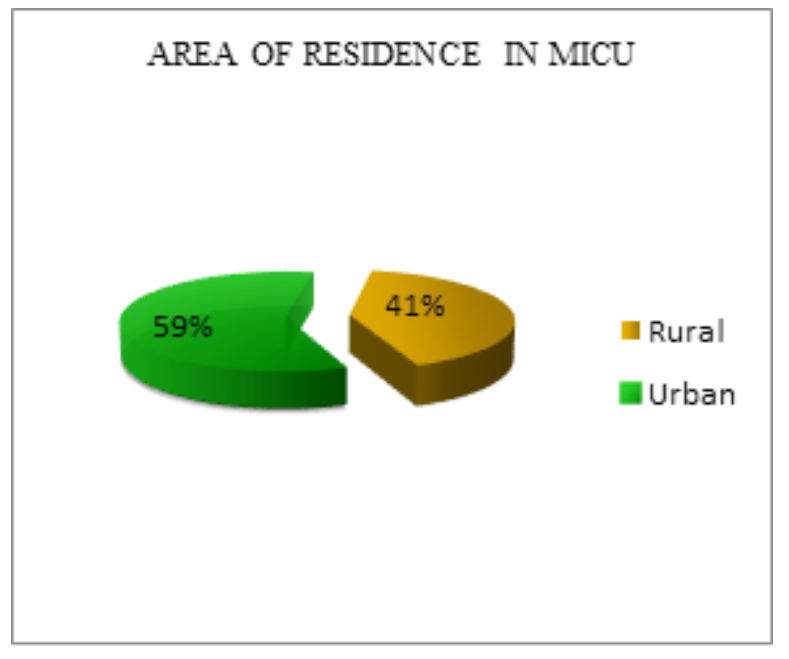

Figure 6: Area of Residence in MICU

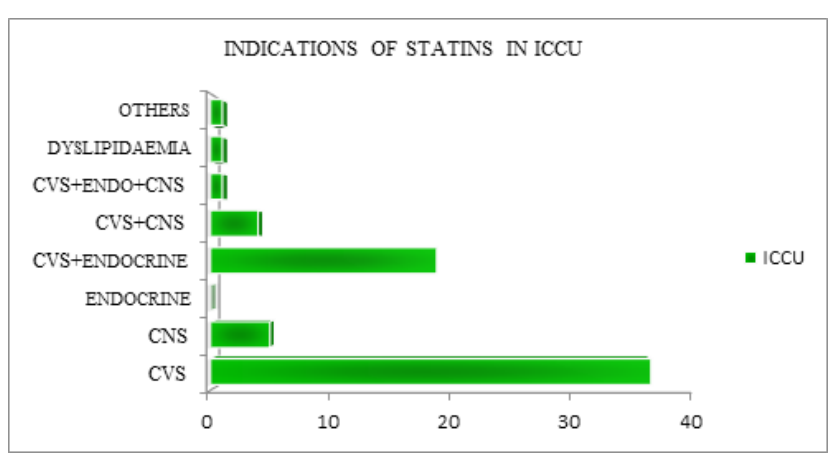

Figure 7: Indications for Statins in ICCU
DDD/100 bed days were calculated by WHO recommended method and it was found to be 7.746 for Atorvastatin, 1.217 for Rosuvastatin in ICCU. This indicates that utilization of Atorvastatin was more, when compared to Rosuvastatin in ICCU. Similarly, DDD/100 bed days was found to be 2.494 for Atorvastatin, 0.147 for Rosuvastatin in MICU. This indicates that utilization of Atorvastatin was more, when compared Rosuvastatin in MICU.

Atorvastatin was prescribed in ICCU under different brand names in which Atorva $(88.2 \%)$ was most commonly prescribed followed by Atorlip (11.1\%). Atorva is manufactured by Zydus Medica. Rosuvastatin was prescribed under the brand name of Rozavel $(66.7 \%)$. It is manufactured by Glenmark. Our results were correlated with study conducted by Praveen K.G in his study, in which brand name of Atorvastatin-Atorva (Zydus Cadila) was more prescribed. Also in MICU, Atorvastatin was prescribed under brand name Atorva $(56.2 \%)$ followed by Aova (20\%). Rosuvastatin was prescribed under brand name Rozavel (60\%).

Study conducted by Praveen Kumar et al, says that more number of male patients have used their medications rationally. Our study conducted in MICU and ICCU support their results. In the age wise distribution of rational and irrational use of Atorvastatin and Rosuvastatin in ICCU patients, we found age groups that is $51-60$ years were more exposed rationally (30.8\%) and irrationally (3\%). In MICU, we found age groups

\begin{tabular}{ccc}
\hline \multicolumn{2}{|c|}{ Table 15: Distribution of risk factors. } \\
\hline Risk factors & No of patients & Percentage (\%) \\
\hline Age > 50 & 73 & 36.5 \\
HTN & 54 & 27 \\
DM & 36 & 18 \\
Smoking & 20 & 10 \\
Drinking & 17 & 8.5 \\
\hline
\end{tabular}

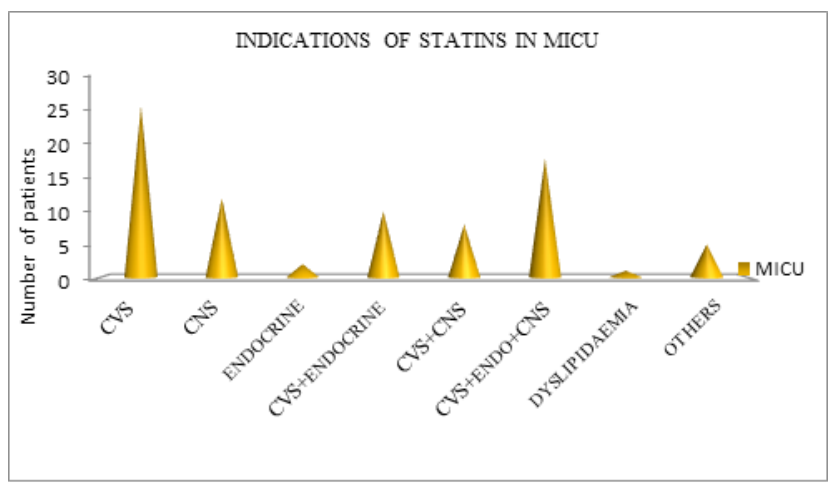

Figure 8: Indications for statins in MICU

Indian Journal of Pharmacy Practice, Vol 10, Issue 4, Oct-Dec, 2017 
61-70 years were exposed more rationally $(33.9 \%)$ and irrationally $(4.9 \%)$.

Patients admitted in ICCU and MICU were mainly with indications related to cardiovascular system, CNS, Dyslipidaemia, Endocrine system and others. Results revealed that more patients were found with indications of cardiovascular system in ICCU (54.4\%). Similarly, in MICU, more patients were admitted with indications related to cardiovascular system (31.7\%). Our study results were supported by Praveen K.G et al and Vinod kumar et al.

Distribution of risk factors among statin consuming patients in ICCU of which Hypertension (21\%) was found to be the major risk factor apart from age $(37.7 \%)$. The MICU results were like that of ICCU that is age (36.5\%) and Hypertension (27\%).

The above study shows that patients who are prescribed with statins have established presence of Hypertension, Diabetes Mellitus, Stroke, Dyslipidaemia, Aortic Stenosis, Ischemic heart disease and other cardiovascular, CNS and Endocrine disorders. This indicates that statin therapy is indispensable as per National Cholesterol Education Programme (NCEP) adult treatment panel (ATP) III. In our study, patients in the age group 51-60 years are mostly exposed in ICCU and age $>70$ groups are mostly affected in MICU. So, geriatric patients are immensely affected. Therefore, they should be provided with vital care.

So, the present study indicates, for the reduced cardiovascular morbidity and mortality, statins are ought to be given on a long-term basis.

\section{CONCLUSION}

Overall, our study demonstrated the importance of DUE and DUE for HMG-COA reductase inhibitors in ICCU and MICU, it is clearly indicating that for the reduced cardiovascular morbidity and mortality the statins are ought to be given on a long-term basis. Early recognition and treatment of dyslipidaemia will drastically reduce the burden of the disease and awareness of this disease process amongst the general population is of utmost importance. Moreover, time to time studies is required to assess drug utilization pattern for improving disease management strategy and quality of life of patients.

\section{ACKNOWLEDGEMENT}

We would like to acknowledge our gratitude towards our parents, friends and Staff of pharmacy practice department, Karavali college of pharmacy and department of pharmacology, Father Muller Medical College Hospital Mangalore, for their co-operation and kind support throughout this study.

\section{ABBREVIATIONS USED}

ICCU: Intensive Coronary Care Unit; MICU: Medical Intensive Care Unit; ICU: Intensive Care Unit; HMGCOA: 3-hydroxy-3-methyl-glutaryl-coenzyme A; OPD: Out Patient Department; TIA: Transient Ischemic Attacks; DDD: Defined Daily Dose.

\section{REFERENCES}

1. Siddiqua A, Jafar H, Tabassum N, Firdous $S$, Tabassum K. Drug utilization evaluation of anti-cancer drugs. Am. J. Pharm. Tech Res. 2014;4(3):690-702.

2. Praveen KG, Arun K. Drug utilization and evaluation of HMG-COA reductase inhibitors in a tertiary care teaching hospital. Indian journal of pharmacy practice. 2013;6(4):56-63.

3. Shalini S, Ravichandran V, Mohanty BK, Dhanaraj SK, Saraswathi R. Drug utilization studies-an overview. International Journal of Pharmaceutical sciences and Nanotechnology. 2010;3(1);803-10.

4. Aleemuddin NM, Farahbahmed MS, Shakeel M, Bashir M, Aamir Ali S, Khatoon MM et al. A Cross-Sectional Study on Prescribing Patterns on Patients Suffering from Respiratory Disorders in a Teaching Hospital of South India. J Cont Med a Dent. 2014;2(1):12-7.

5. Abraham F, Varghese G, Mathew JC, John FM. Drug utilization pattern among geriatric patients. Asian J Pharm Clin Res. 2015;8(6):191-4.

6. Kumar M, Dahiya V, Mishra S, Sharma D, Mishra N, et al. Cardiovascular disease prevalence and drug utilization pattern at a tertiary care teaching hospital in northeastern India. International Journal of Pharmacy and Pharmaceutical sciences. 2016;8(6):116-9.

7. Muhit M, Rahman M, Raihan SZ, Asaduzzaman M, Akbar MA, et al. Cardiovascular disease prevalence and prescription patterns at a tertiary level hospital in Bangladesh. Journal of Applied Pharmaceutical Sciences. 2012;2(3):80-4.

8. Patel PK, Joshi HM, Khandhedia C, Shah H, Shah KN, et al. Study of drug utilization, morbidity pattern and cost of hypolipidemic agents in a tertiary care hospital. International Journal of Basic and Clinical Pharmacology. 2013;2(4):470-5.

9. Johnson P, Siddiq A, Jacob L, Mariya A, Bharathi DR. Evaluation of Prescription Pattern, Adverse Drug Reaction and Cost Analysis of Anti-Hyperlipidemic Drugs. Journal of Medical and Pharmaceutical Innovation. 2016;3(13):4-7.

10. Raj NP, V, Suchandra Sen. Utilization pattern of Statins in an Indian population. International Journal of Pharmacy Teaching and Practices. 2012;3(3):318-24.

11. Nagabushan H, Roopadevi HS, Prakash GM, Pankaja R. A prospective study of drug utilization pattern in cardiac intensive care unit at a tertiary care teaching hospital. International Journal of Basic and Clinical Pharmacology. 2017;4(3):579-83.

12. Raja S, Mohapatra S, Rani RJ. Prescription Patterns of Hypolipidaemic Drugs in a tertiary care hospital of southern India. Journal of Clinical and Diagnostic Research. 2014;8(4):1-3. 